\title{
Removal of Methylene Blue from Water Using Hydroxyapatite Submitted to Microwave Irradiation
}

\author{
Khadija Allam1', Abdeslam El Bouari', Bouchra Belhorma' ${ }^{2}$, Lahcen Bih ${ }^{3}$ \\ ${ }^{1}$ Laboratory of Physical Chemistry of Materials Applied, Department of Chemistry, Faculty of Sciences Ben \\ M'sik, University Hassan II Casablanca, Casablanca, Morocco \\ ${ }^{2}$ National Centre for Energy, Nuclear Science and Technology, CNESTEN, Rabat, Morocco \\ ${ }^{3}$ Group of Physico-Chemical of the Condensed Matter (PCMC), Faculty of Sciences Meknes, University Moulay \\ Ismail, Meknès, Morocco \\ Email: khadijaallam@yahoo.fr
}

Received 10 February 2016; accepted 22 March 2016; published 25 March 2016

Copyright (C) 2016 by authors and Scientific Research Publishing Inc.

This work is licensed under the Creative Commons Attribution International License (CC BY).

http://creativecommons.org/licenses/by/4.0/

(c) (i) Open Access

\section{Abstract}

This study investigated the power of hydroxyapatite adsorbent prepared by a combined precipitation-microwave method, for removing a cationic dye methylene blue in aqueous media. The used adsorbent was characterized by X-ray diffraction (XRD) and infrared spectroscopy (IR). The adsorption tests were conducted in batch mode. The effect of temperature, the $\mathrm{pH}$ of the solution and the mass of the adsorbent on the adsorption were determined. It is found that the adsorption was $\mathrm{pH}$ and temperature dependent. The kinetic study showed that the second-order model gives a better description of the kinetics of the adsorption reaction than the first-order model. Analysis of adsorption isotherms using different classical models showed that adsorption may be governed by the isotherms of Langmuir. The thermodynamic parameters were determined from the values of the maximum adsorption capacity and equilibrium constants.

\section{Keywords}

Microwave, Hydroxyapatite, Methylene Blue, Adsorption, Kinetic, Isotherms

\section{Introduction}

The majority of dyes from different industries such as textile, tannery, and food may generate toxic and carcinogenic substances that present a significant source of environmental contamination when discharged directly 
into the environment without any specific treatment [1]. Therefore, the removal of these contaminants does not only depend on the biological degradation [2]. In this context, several methods have been used: coagulationflocculation [3] precipitation, membrane filtration [4] and electrocoagulation [5]. The adsorption technique is proven as efficient, reliable, and low cost process for removal of pollutants, namely when the adsorbent is abundant and inexpensive [6]. The widely used adsorbent is the active coal despite its relatively high price. The active coal has long remained as the most requested solid because of its very high adsorption capacity, its large specific surface between 400 and $2000 \mathrm{~m}^{2} / \mathrm{g}$, but it can be replaced by other materials able to adsorb organic and inorganic pollutants at lower cost [7]. This has led to a search for materials at low cost as alternative adsorbent materials. In the last decade, hydroxyapatite has known increasing interest for various applications in the biomedical field as bone substitutes [8], bone tissue [9] dental implant [10] and soft tissue repairs [11]; indeed, hydroxyapatite became the basic material used for hard tissue replacement of bone or teeth because of its bio-compatibility and its moldable character. The hydroxyapatite is also widely used for chromatography [12][15] and as nanostructured heterogeneous catalyst for the oxidation reactions, by incorporation of cations such as $\mathrm{Ru}^{3+}$ and $\mathrm{La}^{3+}[16]$. Moreover, hydroxyapatites have also shown their efficiency to remove different species from polluted water or soil [17]-[21]. Many reports have been focused on rapid, low-temperature, and low-cost heating available for elaboration of hydroxyapatite. Recently, new methods of rapid sintering assisted field have been developed. Microwave processing of materials is a technology that can provide a new, powerful, and significantly different tool to process materials or to improve the performance characteristics of existing materials [22]-[24]. Compared with conventional methods this heating offers many advantages including shorter synthesis time, rapid heating, fast reaction, easy reproducibility, narrow particle distribution, high yield, high purity, efficient energy transformation and throughout volume heating. Electricity consumption can be reduced by more than half by using microwave-assisted sintering [25]. It is obvious that the preparation method of the hydroxyapatite could affect its adsorption capacity. Up till now, the reported works on the hydroxyapatite as adsorbent concerned mainly that elaborated by solid state or soft chemistry methods. In the present work, we are interested in studying the adsorption of methylene blue (MB) on hydroxyapatite elaborated by a precipitation process followed by microwave irradiation. Throughout the manuscript this adsorbent is named microwave-HAP. The influence of different parameters on the adsorption such as: the contact time, the initial concentration of $\mathrm{MB}$, the $\mathrm{pH}$ of the solvent is studied. The kinetics and isotherms of the adsorption process are also investigated.

\section{Materials and Methods}

\subsection{Adsorbate}

The removal of organic dyes, especially methylene blue (MB) has been studied by several authors [26]-[28] and showed that it has a very good adsorption affinity and high adsorption on solid supports. Methylene blue (MB) used as pollutant in this study (adsorbate) [8] is a cationic dye (chloride of 3,7-bis(dimethylamino-phenazathionium) index CI 52015; its formula is $\mathrm{C}_{16} \mathrm{H}_{18} \mathrm{~N}_{3} \mathrm{SCl}$, its molecular weight is $319.85 \mathrm{~g} \cdot \mathrm{mol}^{-1}$, and the maximum absorption occurs at wavelength of $664 \mathrm{~nm}$. The chemical structure of MB dye is shown in (Figure 1).

\subsection{Synthesis and Characterization of the Hydroxyapatite (Adsorbent)}

HAP was synthesized by the co-precipitation according to the procedure described elsewhere [29]. The synthesis could be summarized in the following steps. The hydroxyapatite was first synthesized by precipitation from two reagents of calcium nitrate solution $\mathrm{Ca}\left(\mathrm{NO}_{3}\right)_{2} \cdot 4 \mathrm{H}_{2} \mathrm{O}(0.02 \mathrm{~mol}$ in $100 \mathrm{ml}$ of distilled water) and ammonium dihydrogen orthophosphate $\mathrm{NH}_{4} \mathrm{H}_{2}\left(\mathrm{PO}_{4}\right)(0.01 \mathrm{~mol}$ in $100 \mathrm{ml}$ of distilled water). The solution of calcium nitrate was stirred at room temperature with $\mathrm{NH}_{4} \mathrm{H}_{2}\left(\mathrm{PO}_{4}\right)$ solution added by drops. The $\mathrm{pH}$ of this solution was adjusted

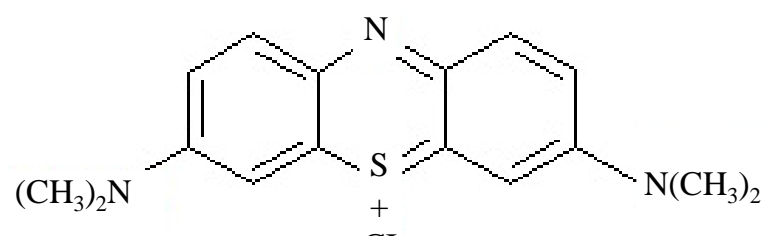

CI

Figure 1. The chemical structure of methylene blue. 
to 9 by adding ammonia solution. The solution is agitated during 24 hours. The resulting precipitate is filtered and washed with distilled water in order to eliminate nitrates. Finally, the obtained precipitate is subjected to a microwave radiation by using a microwave MaRS5 model (power output $1500 \mathrm{~W}$, microwave frequency 245 $\mathrm{MHz}$ ). The mixture was heated in the microwave oven for $3 \mathrm{~min}$.

The identification of the obtained powder was performed by X-ray diffraction (XRD) technique, using a Bruker D8 Advance apparatus. Infrared spectroscopy (IR) was used to identify the vibrational groups of the sample by using a Bruker Tensor 25. Infrared spectra were recorded in the $4500-500 \mathrm{~cm}^{-1}$ region.

\subsection{Adsorption Experiments}

The experiments of adsorption were performed in batch method. The adsorption tests were carried out by introducing an amount of adsorbent precisely weighed into a $100 \mathrm{ml}$ solution of pure methylene blue dye $20 \mathrm{mg} \cdot \mathrm{l}^{-1}$. The samples were taken every 10 minutes after a predetermined contact time. The colored solution was separated from the adsorbent by centrifugation at $2600 \mathrm{rpm}$ for $5 \mathrm{~min}$ and analyzed for MB measurements. The adsorbed quantity was determined by measuring the concentration of the solution before and after adsorption by using the Equation (1). The concentration of the solution was determined using UV-visible spectrophotometer (VWR, V 3100).

$$
q_{e}=\frac{\left(c_{0}-c_{e}\right) \cdot v}{m}
$$

where, $q_{e}(\mathrm{mg} / \mathrm{g})$ is the quantity of the dye adsorbed per unit of adsorbent mass, $C_{0}(\mathrm{mg} / \mathrm{l})$ is the initial dye concentration, $C_{e}(\mathrm{mg} / \mathrm{l})$ is the concentration of dye at the measured time, $m$ the adsorbent mass $(\mathrm{g})$ and $V$ the volume (l) of the adsorption solution.

\section{Results and Discussion}

\subsection{Characterization of the Microwave-HAP}

Figure 2 shows the XRD pattern of the elaborated adsorbent under microwave irradiation. According to the XRD analysis, the pattern shows that the material corresponds to the hydroxyapatite which crystallizes in the hexagonal system with the parameters $a=b=9.41 \AA$ and $c=6.931 \AA$ (JCPDS 74-0566). One can note that no characteristic peaks of impurities such as calcium hydroxide and calcium phosphates were observed. This means that the obtained microwave-HAP phase is pure under the used experimental conditions. Furthermore, the XRD pattern Figure 2 suggests that the synthetized microwave-HAP may be composed of small-sized and poorly crystalline apatite since the characteristic peaks are broad.

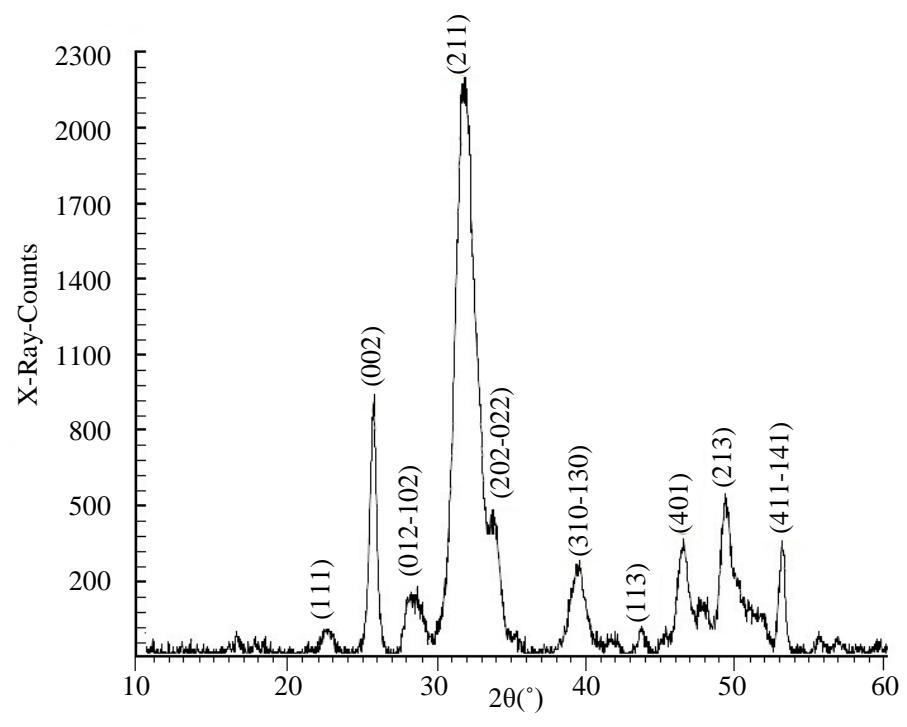

Figure 2. XRD pattern of the microwave-HAP powder. 
The IR spectrum of the sample is presented in Figure 3. The main features of this spectrum reveal the presence of band associated to isolated $\mathrm{PO}_{4}^{3-}$ units, water and/or hydroxyl molecules. Indeed, the spectrum is characterized by two bands at $3250 \mathrm{~cm}^{-1}$ and $1654 \mathrm{~cm}^{-1}$ due to the presence of water in the crystal lattice. One can also observe the presence of two bands at 3450 and $631 \mathrm{~cm}^{-1}$ corresponding to stretching vibration of $\mathrm{OH}$ bonds. Furthermore, the spectrum contains the vibrational modes associated to the phosphate ( $\mathrm{PO}_{4}^{3-}$ ) group: $v_{1}=1352$ $\mathrm{cm}^{-1}, v_{2}=1209 \mathrm{~cm}^{-1}, v_{3}=962 \mathrm{~cm}^{-1}$ and $v_{4}=564 \mathrm{~cm}^{-1}$. In agreement with the XRD analysis, the appearance of the phosphate mode vibration at $962 \mathrm{~cm}^{-1}$ does indicate the crystalline structure of the microwave-HAP phase formation [30]. There is also a low-intensity band at $875 \mathrm{~cm}^{-1}$ which could be ascribed to the structural $\mathrm{HPO}_{4}^{2-}$ entities. From the IR analysis, one can state that the obtained results are in agreement with the XRD analysis since all the structural units contained in the crystalline structure are identified by IR spectroscopy.

\subsection{Influence of Different Parameters on MB Adsorption}

\subsubsection{Effect of Contact Time}

The experiment is performed under the following conditions: mass of microwave-HAP $\mathrm{m}=20 \mathrm{mg}$, ambient temperature $T=25^{\circ} \mathrm{C}$ and $\mathrm{pH}$ of the solution is equal to 6.5. The methylene blue adsorption onto microwaveHAP as a function of contact time is presented in Figure 4. The adsorption capacity increases rapidly to about $30 \mathrm{mg} / \mathrm{g}$ in 4 minutes. After this initial fast adsorption period, the uptake of MB is much slower and no detectable concentration changes occurred after absorption equilibrium (4 min). The same experiment is done by using different initial MB contents but not shown here. The results show that the initial MB concentration has little or no effect on the equilibrium time. It is reported [31] that a fast absorption rate could be due to the absence of internal diffusion resistance which allows the rapidly adsorption of MB from the aqueous solution. The short equilibrium time reveals the efficiency and high adsorptive reaction rate of the synthetized microwave-HAP and suggests its possible uses in practical applications.

\subsubsection{Effect of Solution $\mathrm{pH}$}

The $\mathrm{pH}$ of the dye solution plays an important role in the adsorption process, in particular on the capacity of adsorption. For instance, the value of the $\mathrm{pH}$ affects the efficiency of adsorption since both the order of ionization of the adsorbate and the surface properties of the adsorbent varied with $\mathrm{pH}$ of the solution [32]. The variation of the adsorption as a function of $\mathrm{pH}$ is presented in Figure 5. The $\mathrm{pH}$ of the solution varies from 2 to 12 by using $\mathrm{NaOH}$ solution $(1 \mathrm{~N})$ and $\mathrm{HCl}(1 \mathrm{~N})$. The experiments were performed at ambient temperature by keeping constant the contents of methylene blue and microwave-HAP $(20 \mathrm{mg})$. The percentage of dye removal was calculated by the following Equation (2):

$$
\text { Removal\% }=100 \times \frac{\left(c_{0}-c_{e}\right)}{c_{0}}
$$

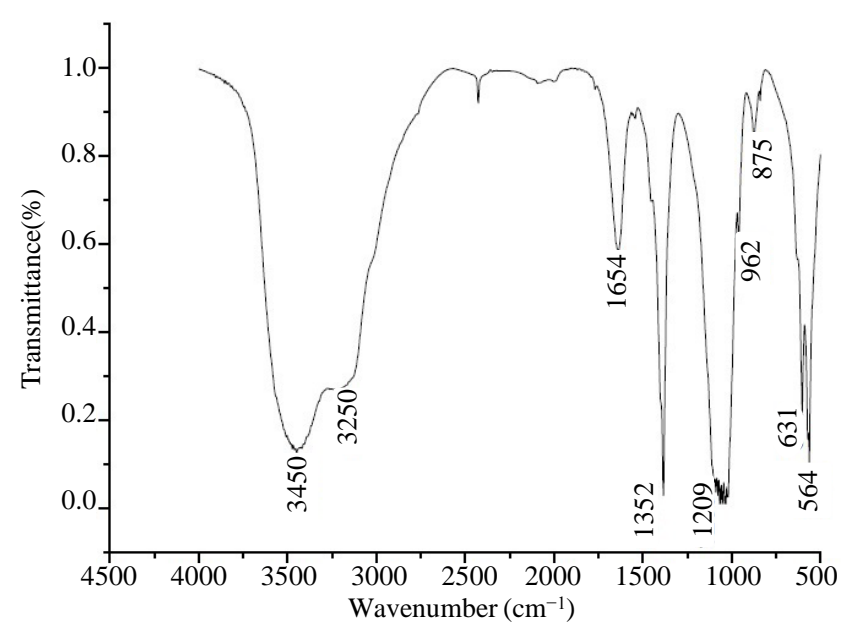

Figure 3. IR Spectrum of the microwave-HAP powder. 


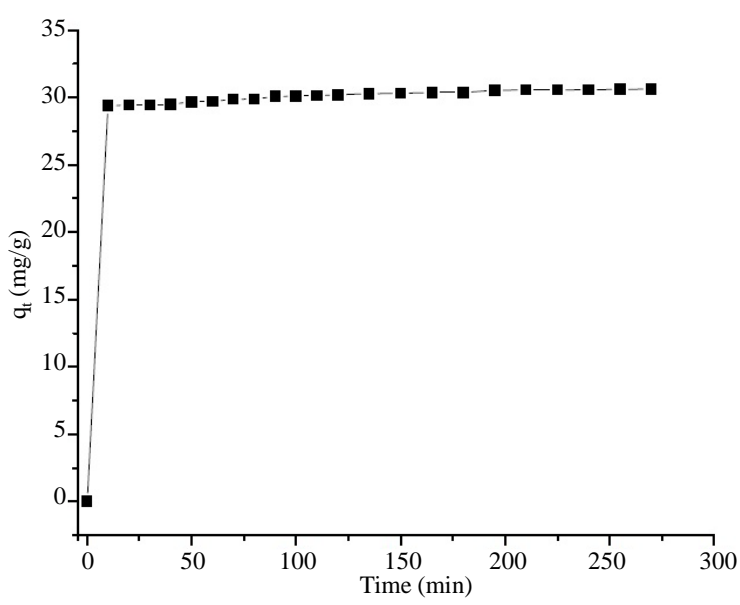

Figure 4. Effect of contact time on methylene blue adsorption.

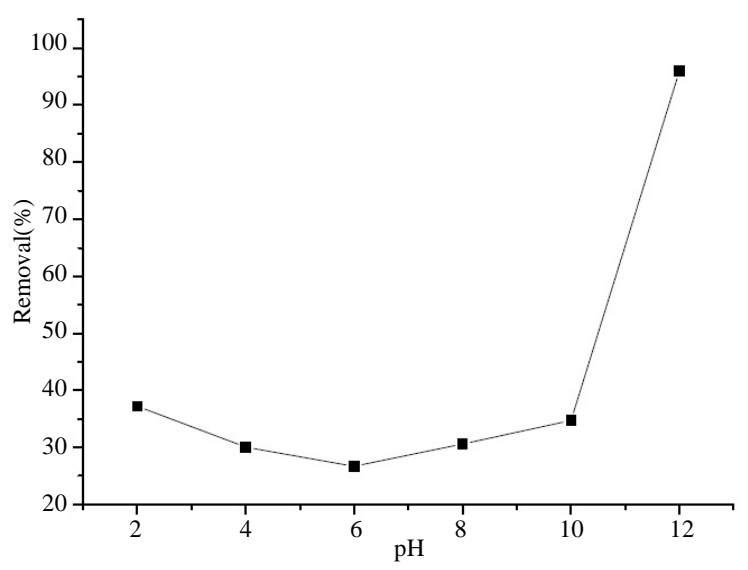

Figure 5. Effect of pH on the removal of methylene blue by microwave-HAP.

where, $C_{0}$ the initial dye concentration (mg/l), $C_{e}$ the equilibrium concentration (mg/l).

From Figure 5, one can see that the percentage of dye adsorption presents a flat minimum in the pH range 6 8. The maximum adsorption is observed at $\mathrm{pH}=12$. When, the solution $\mathrm{pH}$ varies from 2 to 6 , the percentage of adsorption decreases slowly. When the $\mathrm{pH}$ increases from 6 to 12 it induces a rapid increase of the adsorption of MB. These results can be explained by the change in surface charge of the adsorbent and/or the nature of the dye [33]. These authors proposed that while MB dye is a positively charged cation the reactions responsible for the surface properties of HAP in aqueous solutions are:

$$
\begin{gathered}
\equiv \mathrm{PO}^{-}+\mathrm{H}^{+}=\equiv \mathrm{POH} \\
\equiv \mathrm{CaOH}^{2+}=\equiv \mathrm{CaOH}+\mathrm{H}^{+}
\end{gathered}
$$

In the lower $\mathrm{pH}$ region the positively charged $\left(\mathrm{CaOH}^{2+}\right)$ and neutral $\equiv \mathrm{P}-\mathrm{OH}$ sites prevail on HAP surface, making surface charge of HAP positive. In the basic medium neutral $(\mathrm{CaOH})$ and negatively charged $\left(\mathrm{PO}^{-}\right)$species predominated, causing HAP surface to become negatively charged.

Therefore, the point of zero charge ( $\mathrm{pH} \mathrm{pzc}$ ) of the adsorbent is the main parameter influencing the adsorption phenomenon. The $\mathrm{pH}$ pzc value of the hydroxyapatite is found to be in the range $6-7.2$ [34]. When the solution $\mathrm{pH}$ is above the $\mathrm{pH}$ pzc the surface of the hydroxyapatite is negatively charged. At $\mathrm{pH}$ below the $\mathrm{pH} \mathrm{pzc}$, the surface of the hydroxyapatite is positively charged [34] [35]. According to the above, the adsorption of MB as a cationic dye on the adsorbent microwave-HAP could be explained as follow: the electrostatic attraction between the negatively charged surface of the microwave-HAP and the positively charged group of the dye is more sig- 
nificant at $\mathrm{pH}$ above 7.2 hence the percentage of adsorption of the dye increases. On the contrary, in the acidic medium positively charged surface sites on microwave-HAP and MB cations are submitted to electrostatic repulsions which do not favor the adsorption of MB. Indeed, when the solution is acidic the competition of excess protons $\left(\mathrm{H}^{+}\right)$with MB cations for active adsorption sites in microwave-HAP could also explain the lower adsorption. Similar behavior has been observed elsewhere [36]. However, despite the electrostatic repulsion and/or $\mathrm{H}^{+}$competition a considerable amount of MB was adsorbed by microwave-HAP at lower $\mathrm{pH}$ values (Figure 5), which suggested that other mechanisms might involve in the MB adsorption process. One possible mechanism is related to that reported in the literature [37] [38]. It was reported that a strong H-bonding interaction between $(\mathrm{P}-\mathrm{OH})$ group of HAP particles and $(\mathrm{N})$ of the MB molecule could contributed toward adsorption of MB molecules [37]. Indeed, the nitrogen atom of MB might interact with $\mathrm{Ca}^{2+}$ groups of HAP via Lewis acid-base interaction [38]. A representative scheme of different possible interactions of MB with the HAP surface is given in Figure 6. In general, we can consider that at an acidic media, adsorption mechanisms involves (2) and (3) modes while in a basic one, adsorption mechanisms involves (1) and (2) interactions.

\subsubsection{Effect of Temperature and Thermodynamic Parameters of the Process}

To investigate the influence of temperature on the adsorption of MB onto the microwave-HAP we have carried out isotherm studies at four temperatures $25^{\circ} \mathrm{C}, 45^{\circ} \mathrm{C}, 65^{\circ} \mathrm{C}$ and $75^{\circ} \mathrm{C}$. During the measurements, the mass $(20$ $\mathrm{mg}$ ) of the adsorbent, the concentration of $\mathrm{MB}\left(20 \mathrm{mg} \cdot \mathrm{l}^{-1}\right)$, the contact time and the $\mathrm{pH}(6.5)$ were kept constant. The variation of the adsorbed capacity of $\mathrm{MB}$ as a function of the temperature is plotted in Figure 7 . It is observed that the adsorption depends strongly on the temperature. For instance, the increase in the temperature from $25^{\circ} \mathrm{C}$ to $75^{\circ} \mathrm{C}$ induces an increase in the capacity of the adsorption from $28.371 \mathrm{mg} / \mathrm{g}$ to $33.504 \mathrm{mg} / \mathrm{g}$. This could be due to the increase of the diffusion rate MB molecules on the outer layer of the adsorbent surface; this increase has a positive effect on adsorption [39]. To get more insight the adsorption process, the thermodynamic parameters such as standard enthalpy change $\left(\Delta H^{\circ}\right)$, the Gibbs free energy change $\left(\Delta G^{\circ}\right)$ and standard entropy change $\left(\Delta S^{\circ}\right)$ have been determined using the following equations:

$$
\begin{gathered}
\Delta G^{\circ}=-R T \ln \left(K_{D}\right) \\
\ln K_{D}=-\frac{\Delta H^{\circ}}{R T}+\frac{\Delta S^{\circ}}{R}
\end{gathered}
$$

where $R$ is the universal gas constant $(8.314 \mathrm{~J} / \mathrm{mol} \cdot \mathrm{K})$ and $T$ is solution temperature in $\mathrm{K}$.

The equilibrium constant $\left(K_{D}\right)$ can be calculated using the below equation:

$$
K_{D}=\frac{q_{e}}{C_{e}}
$$

Equilibrium constant $\left(K_{D}\right)$ for the adsorption process was determined by plotting $\ln q_{e} / C_{e}$ vs $q_{e}$ and extrapolating to zero $q_{e}[40]$. By ploting $\ln K_{D}$ versus $1 / T$ as shown in Figure 8 one can calculate values of $\Delta H^{\circ}$ and $\Delta S^{\circ}$.

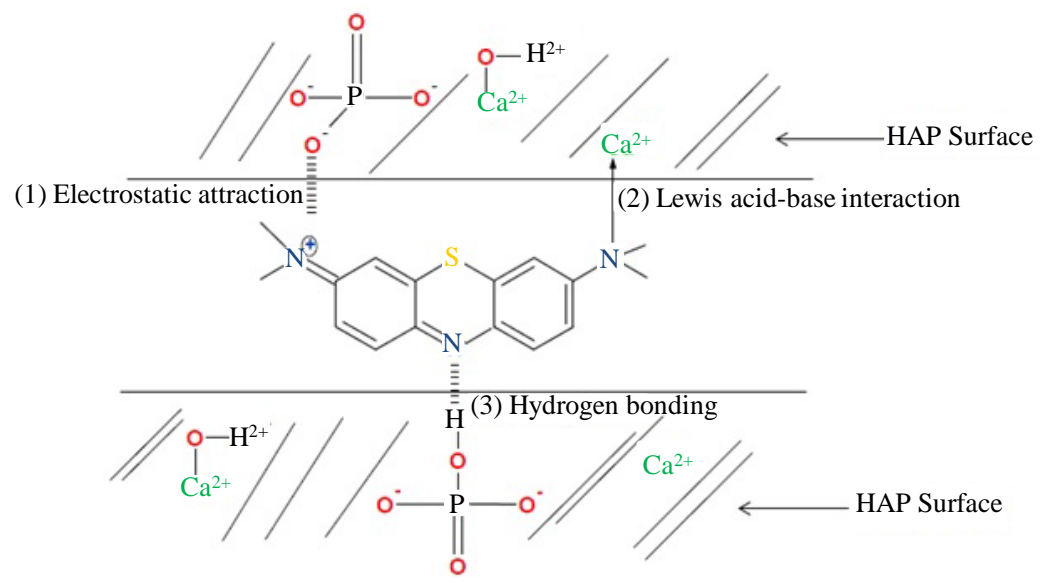

Figure 6. Schematic representation of the possible interactions between microwave-HAP and MB at various $\mathrm{pH}$ values. 


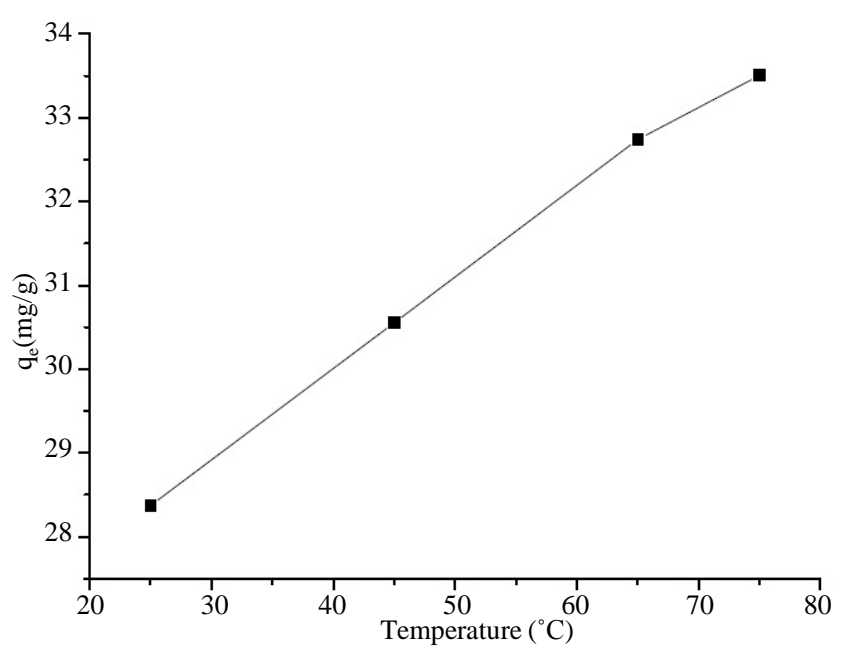

Figure 7. Effect of temperature on the adsorption of MB on microwave-HAP.

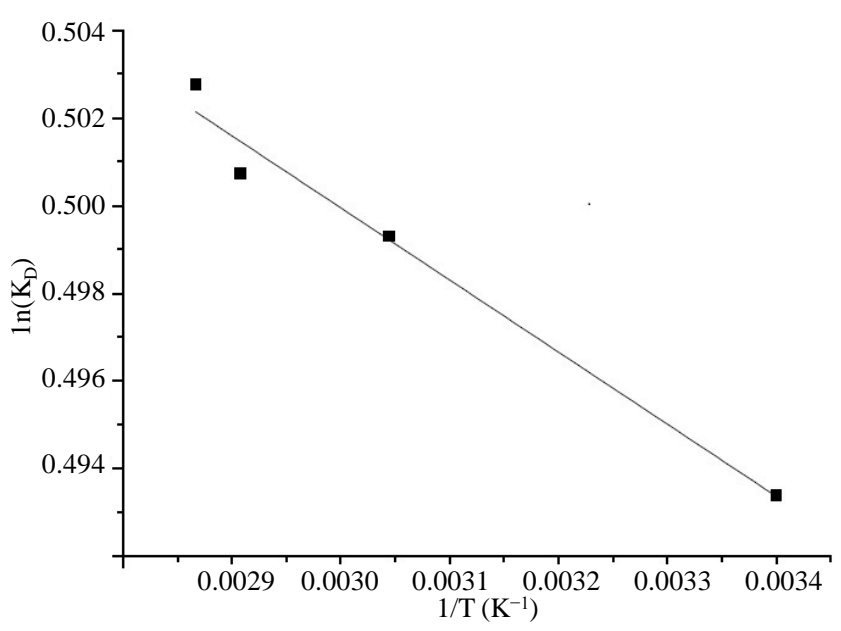

Figure 8. Plots of $\ln \left(K_{d}\right)$ versus $1 / T$ for the adsorption of MB on microwave-HAP.

The above thermodynamic parameters are determined and are gathered in Table $1 . \Delta H^{\circ}$ and $\Delta S^{\circ}$ determined for the different temperatures have the same values to that obtained for the temperature $298 \mathrm{~K}$. The positive value of $\Delta H^{\circ}$ suggests the endothermic nature of the adsorption, which is supported by the increase of the adsorption capacity of MB onto the microwave-HAP with the temperature (Figure 7). Based on $\Delta H^{\circ}$ value which it is a small positive value compared to $40 \mathrm{~kJ} / \mathrm{mol}$ [41] one can state that the adsorption of MB onto microwave-HAP could be a physisorption process. The positive value of $\Delta S^{\circ}$ depicts the increasing degree of disorder at the solid-liquid interface during the adsorption of methylene blue [26] [42]. Besides, it is clear to see that the values of free energy $\Delta G^{\circ}$ at all of the tested temperatures were negative, this confirms that the adsorption is spontaneous and thermodynamically favorable [43]. Generally, the change in free energy $\Delta G^{\circ}$ in the case of physical adsorption ranges from -20 to $0 \mathrm{~kJ} / \mathrm{mol}$ and in the case of chemical adsorption it ranges from -80 to $-400 \mathrm{~kJ} / \mathrm{mol}$ [44]. This further indicated that the physisorption might dominate the adsorption of MB onto microwave-HAP.

\subsubsection{Effect of the Adsorbent Mass}

The effect of the adsorbent mass was studied at constant temperature while keeping $\mathrm{pH}$ at 6.5 and the dye concentration at $20 \mathrm{mg} \cdot \mathrm{l}^{-1}$. The used adsorbent masses are 20, 40, 60, 80, $100 \mathrm{and} 200 \mathrm{mg}$. The removal percentage of the dye was calculated by the Equation (2). Figure 9 depicts the mass dependence of the dye removal. It is 
Table 1. Thermodynamic parameters for MB adsorption at equilibrium on microwave-HAP.

\begin{tabular}{cccc}
\hline$T(\mathrm{~K})$ & $\Delta G^{\circ}\left(\mathrm{kJ} \cdot \mathrm{mol}^{-1}\right)$ & $\Delta H^{\circ}\left(\mathrm{kJ} \cdot \mathrm{mol}^{-1}\right)$ & $\Delta S^{\circ}\left(\mathrm{J} \cdot \mathrm{mol}^{-1} \cdot \mathrm{K}^{-1}\right)$ \\
\hline 298 & -0.44 & 0.81 & 4.21 \\
318 & -0.53 & & \\
338 & -0.61 & \\
348 & -0.65 & \\
\hline
\end{tabular}

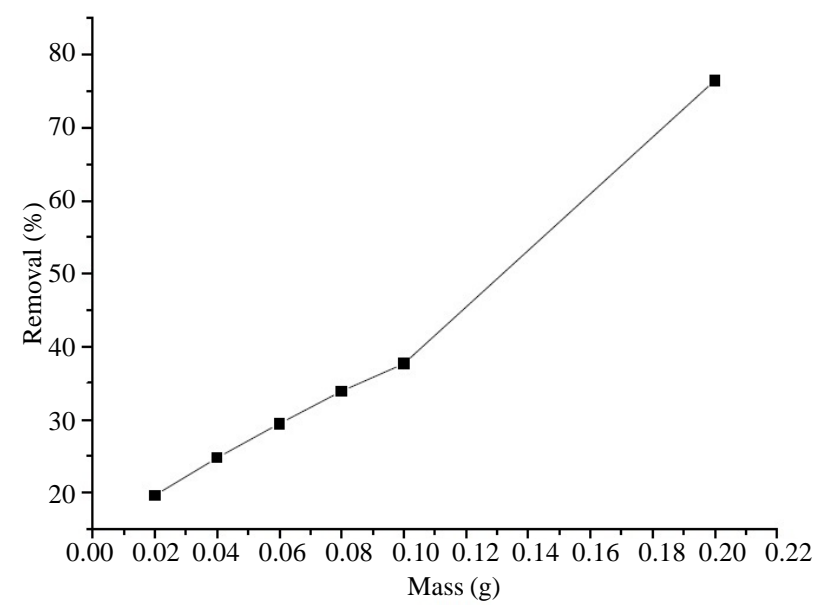

Figure 9. Effect of the adsorbent mass on the adsorption of BM.

observed that the adsorption of MB increases when the mass of adsorbent increases. This improvement can be justified by the increase of the adsorption sites with increasing mass. This favors therefore the discoloration phenomenon [45].

\section{Isotherm Studies}

The adsorption isotherms describe the distribution of the MB dye between the solution and the microwave-HAP adsorbent when the adsorption process reaches an equilibrium state. There are several applicable isotherm models, but the most widely used are the Langmuir and the Freundlich models [46] [47] the adsorption isotherms data were analyzed according to these two models as described below.

The Langmuir equation is adapted to describe the adsorption behavior of homogeneous surfaces. The adsorption Langmuir model is applied on the following assumptions: 1) strong uniform adsorption sites, 2) the monolayer coverage, and 3) no lateral interaction between adsorbed molecules. The linear form of this isotherm is represented as follows [48]:

$$
\frac{1}{q}=\frac{1}{q_{m}}+\frac{1}{K_{L} \cdot q_{m}} \times \frac{1}{C_{e}}
$$

where $q_{e}(\mathrm{mg} / \mathrm{g})$ is the amount of dye adsorbed at equilibrium, $C_{e}(\mathrm{mg} / \mathrm{l})$ is the equilibrium concentration, $K_{L}(\mathrm{l} / \mathrm{g})$ is the Langmuir constant and $q_{m}$ is the monolayer adsorption capacity.

In addition, the essential feature of the Langmuir isotherm can be expressed by a dimensionless term called the $R_{L}$ separation factor. This factor is used to predict whether an adsorption system is "favorable” or "unfavorable”. It is defined [19] as:

$$
R_{L}=\frac{1}{1+K_{L} \cdot C_{0}}
$$

On the other hand Freundlich isotherm approves the heterogeneity of the surface and assumes that the absorption occurs on sites with different adsorption energy. The adsorption energy varies depending on the coverage area [49]. Equation (8) represents the Freundlich isotherm. 


$$
q_{e}=K_{F} C_{e}^{1 / n}
$$

where $q_{e}$ is the amount of solute adsorbed per unit weight of adsorbent $\left(\mathrm{mg} \cdot \mathrm{g}^{-1}\right), C_{e}$ is the equilibrium concentration, $K_{F}$ is the Freundlich constant and $(n)$ is the heterogeneity factor. The value $K_{F}$ is related to the adsorption capacity, while the value of $(1 / n)$ is related to the adsorption intensity. When $n=1$, the adsorption is linear, meaning that sites are homogeneous and there is no interaction between the adsorbed species; when $1 / n<1$, adsorption is favorable and the adsorption capacity increases while new adsorption sites appear. When $1 / n>1$ adsorption is not favorable, adsorption bonds become weak and the adsorption capacity decreases [50].

Let us now to consider the above models. The Langmuir isotherm equation (Equation (6)) was applied to the adsorption data to quantify the adsorption capacity of the microwave-HAP powders. The Langmuir plot (Figure 10) of the data displayed a good linear fit and the derived $q_{m}$ and $K_{L}$ parameters from slope and intercept are presented in Table 2. From this latter, one can note that the correlation coefficient $R^{2}\left(R^{2}=0.9968\right)$ is very close to 1 and the maximum adsorption capacity is $33.3 \mathrm{mg} / \mathrm{g}$.

The calculated value of $R_{L}$ is 0.1 which indicates that the adsorption is favorable. This good correlation between the data and the Langmuir adsorption model assumes monolayer coverage of $\mathrm{MB}$ on homogeneous sites of microwave-HAP, uniform energy of adsorption, and no interaction between MB species adsorbed on neighboring sites.

In parallel, the adsorption data was also plotted using the Freundlich model under the same experimental conditions (Figure 11). The numerical values of $K_{f}$ and $(1 / n)$ calculated are gathered in Table 2. The numerical value of $1 / n=0.2$ indicates that the adsorption using heterogeneous sites is favorable. Nevertheless, based on the correlation coefficient $\left(R^{2}\right)$ values in the present study, the Langmuir isotherm provides the best fit for the experimental data.

According to the obtained results, it seems that the microwave irradiation of the hydroxyapatite is very benefit for the adsorption of the MB since the adsorption parameters are improved compared to that obtained for nonirradiated hydroxyapatites [51] [52].

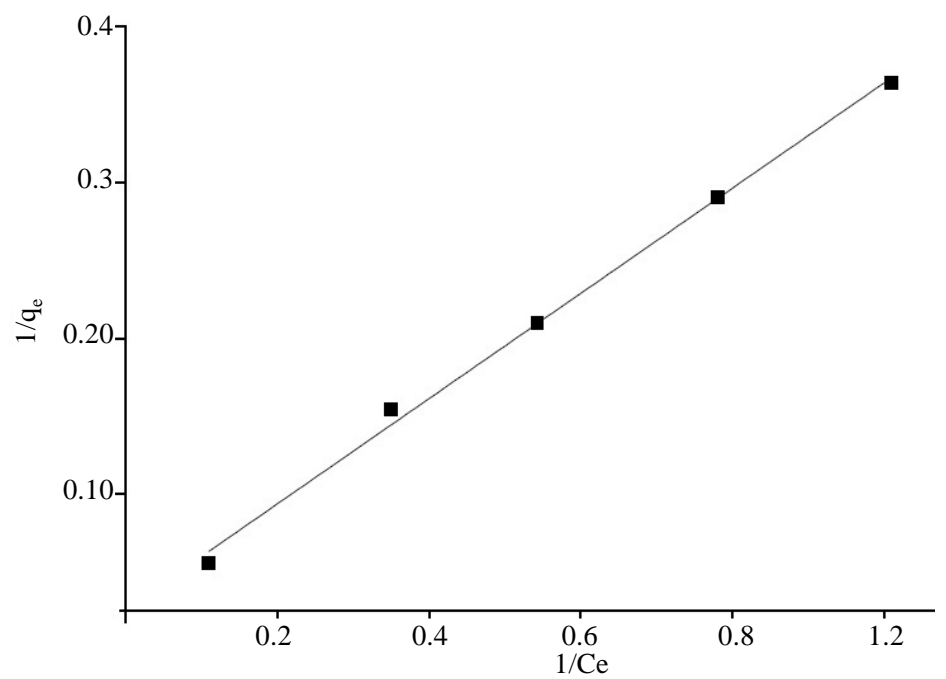

Figure 10. Langmuir plot for BM adsorption on microwave-HAP.

Table 2. The adsorption parameters for Freundlich and Langmuir models.

\begin{tabular}{cc}
\hline Isotherme of Langmuir & Isotherme of Freundlich \\
\hline$K_{L}(\mathrm{l} / \mathrm{mg}) 0.5$ & $K_{f}(\mathrm{l} / \mathrm{Kg}) 0.01$ \\
$q_{m}(\mathrm{mg} / \mathrm{g}) 33.3$ & $n 0.2$ \\
$R^{2} 0.9968$ & $R^{2} 0.9817$ \\
$R_{L} 0.1$ & \\
\hline
\end{tabular}




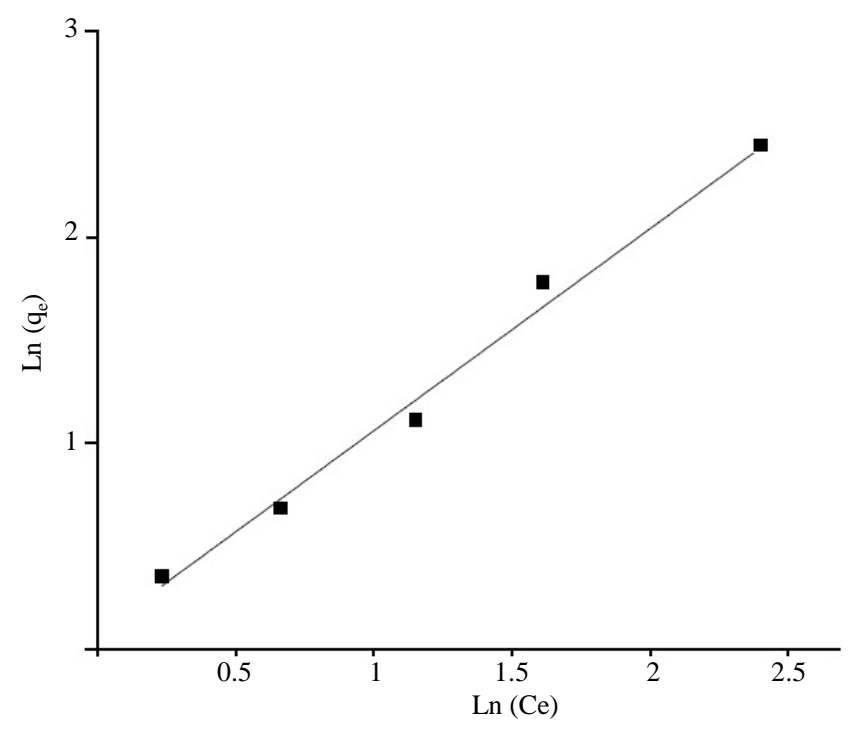

Figure 11. Freundlich plot for BM adsorption on microwaveHAP.

In order to assess the performance of microwave-HAP as an adsorbent for MB, the adsorption capacity of microwave-HAP were compared with those of other adsorbents examined for the removal of MB in the literature Table 3. The maximum adsorption of $\mathrm{MB}$ is $33.3 \mathrm{mg} \cdot \mathrm{g}^{-1}$, which is significantly higher than the other adsorbents listed in Table 3.

\section{Kinetics Studies}

Several formalisms are given in the literature to describe the adsorption kinetics. All these formalisms bring some information on the adsorption rate and mechanism of the adsorption. In this study, two models were applied to describe the adsorption kinetic mechanism: the pseudo-first-order and the pseudo-second-order model [53].

The kinetic model of the pseudo-first-order is expressed as follows:

$$
\frac{d_{q_{t}}}{d_{q}}=k_{1}\left(q_{e}-q_{t}\right)
$$

where $q_{e}$ and $q_{t}$ are adsorption capacity (mg/g) at equilibrium and at time $t$, respectively. $k_{1}$ is the adsorption rate constant $\left(\mathrm{min}^{-1}\right)$.

After integration and application of boundary conditions this model can be expressed in a linear form as Equation (10):

$$
\log \left(q_{e}-q_{t}\right)=\log \left(q_{e}\right)-k_{1} \cdot \frac{t}{2.303}
$$

The plot of $\log \left(q_{e}-q_{t}\right)$ versus $(t)$ is given in Figure 12. From this figure one can extract the values of $k_{1}$ and $q_{e}$ parameters and they are given in Table 4.

It is clear from the analysis of $\log \left(q_{e}-q_{t}\right)$ according to time that it is not linear, and consequently the adsorption of methylene blue on microwave-HAP cannot be described by the pseudo-first order.

After this conclusion, we have applied the second model to fit the experimental data obtained from the kinetic experiments. The linear form of the equation of pseudonym second-order is expressed as follows:

$$
\frac{t}{q_{t}}=\frac{1}{K_{2} \cdot q_{e}^{2}}+\frac{t}{q_{e}}
$$

where $q_{e}$ and $q_{t}$ designate the absorption capacity $(\mathrm{mg} / \mathrm{g})$ at equilibrium and time $t$, respectively. A constant $k_{2}$ represents the constant rate of adsorption (g/mg·min).

The parameters $q_{e}$ and $k_{2}$ are obtained by representing $t / q_{t}$ versus $t$ (Figure 13). The obtained values for these parameters are gathered in Table 4. 
Table 3. Maximum adsorption capacity of MB onto various types of adsorbent relative to Langmuir model.

\begin{tabular}{ccc}
\hline Adsorbents & Maximum adsorption $\left(\mathrm{mg} \cdot \mathrm{g}^{-1}\right)$ & References \\
\hline HAP & 0.7 & This study \\
Microwave-HAP & 33.3 & This study \\
Poorly crystalline HAP & 14.27 & {$[52]$} \\
HAP & 0 & {$[51]$} \\
\hline
\end{tabular}

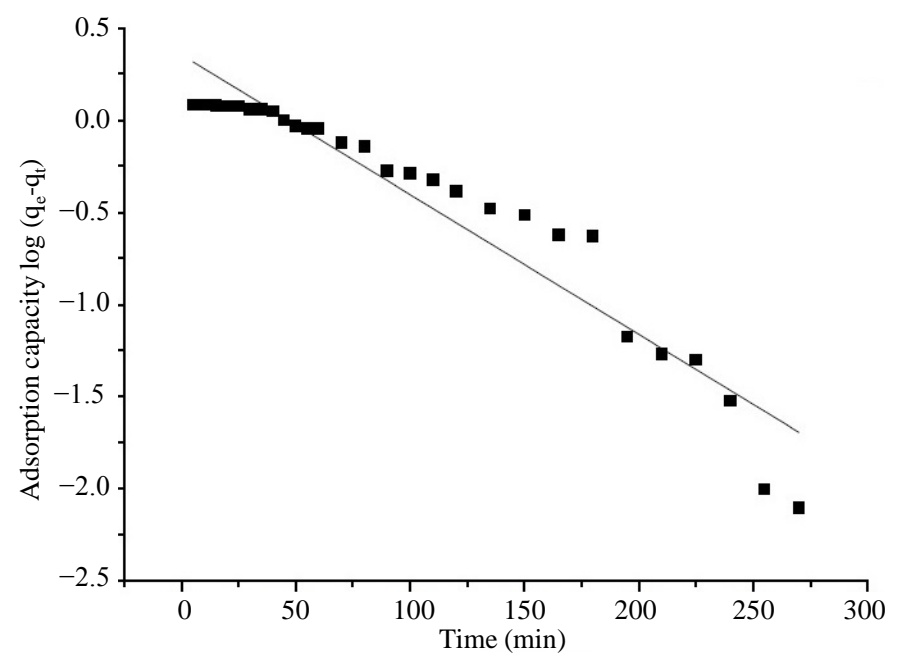

Figure 12. $\log \left(q_{e}-q_{t}\right)$ versus time according to the first-order kinetic model ( $\mathbf{\square}$ : experiment ; __ fit linear).

Table 4. Adsorption capacity, rate constant and correlation coefficient obtained from the studied kinetic models.

\begin{tabular}{ccccccc}
\hline \multirow{2}{*}{$q_{\mathrm{e}, \mathrm{exp}}(\mathrm{mg} / \mathrm{g})$} & \multicolumn{3}{c}{ Pseudo-first order } & \multicolumn{3}{c}{ Pseudo-second order } \\
\cline { 2 - 7 } & $q_{\mathrm{e}, \text { calc }}(\mathrm{mg} / \mathrm{g})$ & $K_{1}(\mathrm{~min})$ & $R^{2}$ & $q_{\mathrm{e}, \text { calc }}(\mathrm{mg} / \mathrm{g})$ & $K_{1}(\mathrm{~g} / \mathrm{min} \cdot \mathrm{mg})$ & $R^{2}$ \\
\hline 30.61 & 2.11 & 0.016 & 0.9196 & 30.67 & 0.022 & 1 \\
\hline
\end{tabular}

The linear variation (Figure 13) of $t / q_{t}$ with the time suggests that the pseudo-second order model describes well the kinetic behavior of the methylene blue adsorption on microwave-HAP. The experimental data can be fitted with the equation:

$t / q_{t}=0.0326 t+0.0476$, with a correlation coefficient $R^{2}=1$.

The analysis of the data given in Table 4 showed perfectly that the experimental adsorption capacity $q_{e}$ is very close to that obtained by the pseudo second order model. Therefore, according to this latter model, we can state that the adsorption of methylene blue on the microwave-HAP involves the chemisorption process in addition to the physisorption.

\section{Conclusion}

In the present work we have tested the adsorption of the cationic dye MB on the hydroxyapatite elaborated using a combined precipitation and microwave irradiation technique. The results show that the adsorption kinetic of the dye on microwave-HAP is well described by the second-order model. The adsorption isotherms are described satisfactorily by the Langmuir model. The temperature has a positive effect on the adsorption of MB suggesting that its adsorption is an endothermic process. The dye adsorption was also influenced by the $\mathrm{pH}$ of the solution. The percentage of adsorption of the dye decreases as the medium $\mathrm{pH}$ increases up to 6 . With further increase of $\mathrm{pH}$ the percentage of adsorption of the dye increases rapidly. This behavior is correlated with the change of the electrostatic charges on the surface of the hydroxyapatite. It is also shown that the microwave irradiation has a positive effect on the adsorption. 


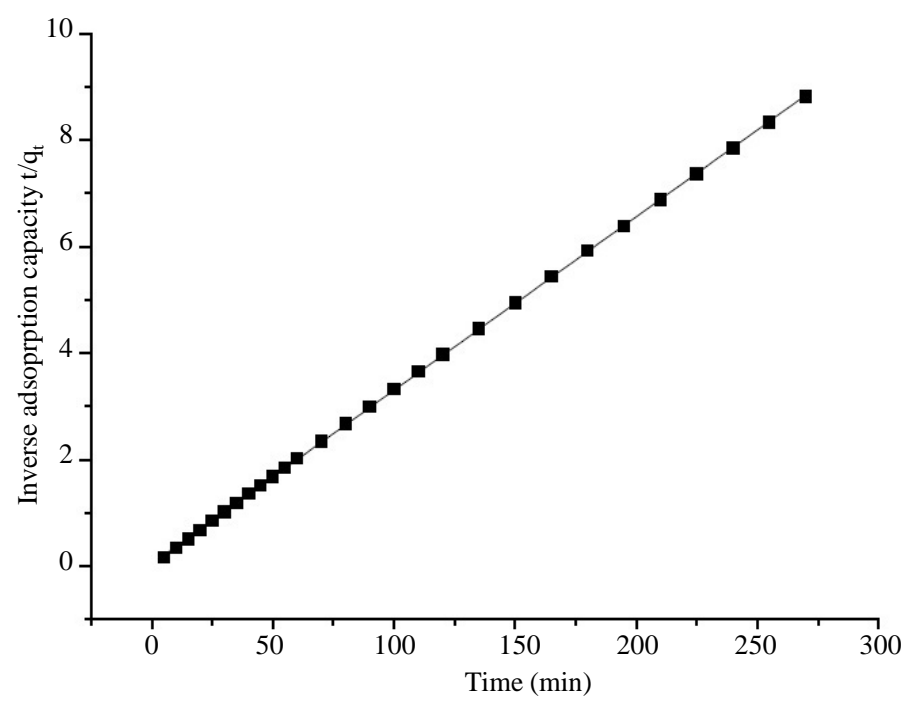

Figure 13. Second order kinetic model applied to the adsorption of MB on the microwave-HAP ( $\square$ : experiment ; _ fit linear).

\section{Acknowledgements}

The authors acknowledge the Institute for Research in Solar Energy and New Energies (IRESEN) for the financial support.

\section{References}

[1] Hamdaoui, O., Saoudi, F., Chiha, M. and Naffrechoux, E. (2008) Sorption of Malachite Green by a Novel Sorbent, Dead Leaves of Plane Tree: Equilibrium and Kinetic Modeling. Chemical Engineering, 143, 73-84. http://dx.doi.org/10.1016/j.cej.2007.12.018

[2] Kannan, N. and Sundaram, M.M. (2001) Kinetics and Mechanism of Removal of Methylene Blue by Adsorption on Various Carbons-A Comparative Study. Dyes and Pigments, 51, 25-40. http://dx.doi.org/10.1016/S0143-7208(01)00056-0

[3] Kacha, S., Ouali, M.S. and Elmaleh, S. (1997) Dye Abatement of Textile Industry Wastewater with Bentonite and Aluminium Salts. Water Science, 10, 233-248.

[4] Gücek, A., Sener, S., Bilgen, S. and Mazmanc, M.A. (2005) Adsorption and Kinetic Studies of Cationic and Anionic Dyes on Pyrophyllite from Aqueous Solutions. Colloid and Interface Science, 286, 53-60. http://dx.doi.org/10.1016/j.jcis.2005.01.012

[5] Shin, H.S. and Lee, J.K. (2006) Performance Evaluation of Electrocoagulation and Electro Dewatering System for Reduction of Water Content in Sewage Sludge. Chemical Engineering Journal, 23, 188-193.

[6] Bhatnagar, A. and Sillanpaa, M. (2010) Utilization of Agro-Industrial and Municipal Waste Materials as Potential Adsorbents for Water Treatment. Chemical Engineering Journal, 157, 277-296. http://dx.doi.org/10.1016/j.cej.2010.01.007

[7] Nethaji, S., Sivasamy, A. and Mandal, A.B. (2013) Adsorption Isotherms, Kinetics and Mechanism for the Adsorption of Cationic and Anionic Dyes onto Carbonaceous Particles Prepared from Juglansregia Shell Biomass. Environmental Science \& Technology, 10, 231-242.

[8] Rafatullah, M., Sulaiman, O., Hashim, R. and Ahmad, A. (2010) Adsorption of Methylene Blue on Low-Cost Adsorbents: A Review. Hazardous Materials, 177, 70-80. http://dx.doi.org/10.1016/j.jhazmat.2009.12.047

[9] Ignjatovic, N. and Uskokovic, D. (2004) Synthesis and Application of Hydroxyapatite/Polylactide Composite Biomaterial. Applied Surface Science, 238, 314-319. http://dx.doi.org/10.1016/j.apsusc.2004.05.227

[10] Watari, F., Yokoyama, A., Saso, F., Uo, M. and Kawasaki, T. (1997) Fabrication and Properties of Functionally Graded Dental Implant. Composites Part B, 28B, 5-11. http://dx.doi.org/10.1016/S1359-8368(96)00021-2

[11] Ji, Y.D., Kuo, T.F., Wua, H.D., Yangc, J.C. and Lee, S.Y. (2012) A Novel Injectable Chitosan/Polyglutamate Polyelectrolyte Complex Hydrogel with Hydroxyapatite for Soft-Tissue Augmentation. Carbohydrate Polymers, 89, 11231130. http://dx.doi.org/10.1016/j.carbpol.2012.03.083 
[12] Kadoya, T., Isobe, T., Ebihara, M., Ogawa, T., Sumita, M., Kuwahara, H., Kobayashi, A., Ishikawa, T. and Okuyama, T. (1986) A New Spherical Hydroxyapatite for High Performance Liquid Chromatography of Proteins. Liquid Chromatography, 9, 3543-3557. http://dx.doi.org/10.1080/01483918608077803

[13] Kawasaki, T., Niikura, M. and Kobayashi, Y. (1990) Fundamental Study of Hydroxyapatite Liquid Chromatography High-Performance. Chromatography, 515, 125-148. http://dx.doi.org/10.1016/S0021-9673(01)89307-9

[14] Pinto, G., Caira, S., Mamone, G., Ferranti, P., Addeo, F. and Picariello, G. (2014) Fractionation of Complex Lipid Mixtures by Hydroxyapatite Chromatography for Lipidomic Purposes. Chromatography A, 1360, 82-92. http://dx.doi.org/10.1016/j.chroma.2014.07.093

[15] Cleland, T.P. and Vashishth, D. (2015) Bone Protein Extraction without Demineralization Using Principles from Hydroxyapatite Chromatography. Analytical Biochemistry, 472, 62-66. http://dx.doi.org/10.1016/j.ab.2014.12.006

[16] Aissa, A., Debbabi, M., Gruselle, M., Thouvenot, R., Flambard, A., Patrick, G., Beaunier, P. and Tõnsuaadu, K. (2009) Sorption of Tartrate Ions to Lanthanum (III)-Modified Calcium Fluor- and Hydroxyapatite. Journal of Colloid and Interface Science, 330, 20-28. http://dx.doi.org/10.1016/j.jcis.2008.10.043

[17] Smiciklas, I., Dimovic, S., Plecas, I. and Mitric, M. (2006) Removal of $\mathrm{Co}^{2+}$ from Aqueous Solutions by Hydroxyapatite. Water Research, 40, 2267-2274. http://dx.doi.org/10.1016/j.watres.2006.04.031

[18] Lin, K., Pan, J., Chen, Y., Cheng, R. and Xu, X. (2009) Study the Adsorption of Phenol from Aqueous Solution on Hydroxyapatite Nanopowders. Journal of Hazardous Materials, 161, 231-240. http://dx.doi.org/10.1016/j.jhazmat.2008.03.076

[19] Sljivi, M., Smiciklas, I., Plecas, I. and Mitri, M. (2009) The Influence of Equilibration Conditions and Hydroxyapatite Physico-Chemical Properties onto Retention of $\mathrm{Cu}^{2+}$ Ions. Chemical Engineering Journal, 148, 80-88. http://dx.doi.org/10.1016/j.cej.2008.08.003

[20] Fenga, Y., Gonga, J.L., Zenga, G.M., Niua, Q.Y., Zhanga, H.Y., Niua, C.G., Denga, J.H. and Yana, M. (2010) Adsorption of Cd (II) and Zn (II) from Aqueous Solutions Using Magnetic Hydroxyapatite Nanoparticles as Adsorbents. Chemical Engineering Journal, 162, 487-494. http://dx.doi.org/10.1016/j.cej.2010.05.049

[21] Mourabet, M., El Rhilassi, A., El Boujaady, H., Bennani-Ziatni, M., El Hamri, R. and Taitai, A. (2015) Removal of Fluoride from Aqueous Solution by Adsorption on Hydroxyapatite (HAp) Using Response Surface Methodology. Journal of Saudi Chemical Society, 19, 603-615. http://dx.doi.org/10.1016/j.jscs.2012.03.003

[22] Meejoo, S., Maneeprakorn, W. and Winotai, P. (2006) Phase and Thermal Stability of Nanocrystalline Hydroxyapatite Prepared via Microwave Heating. Thermochimica Acta, 447, 115-120. http://dx.doi.org/10.1016/j.tca.2006.04.013

[23] Han, J.K., Song, H.Y., Saito, F. and Lee, B.T. (2006) Synthesis of High Purity Nano-Sized Hydroxyapatite Powder by Microwave-Hydrothermal Method. Materials Chemistry and Physics, 99, 235-239. http://dx.doi.org/10.1016/j.matchemphys.2005.10.017

[24] Das, S., Mukhopadhyay, A.K., Datta, S. and Basu, D. (2009) Prospects of Microwave Processing: An Overview. Bulletin of Materials Science, 32, 1-13. http://dx.doi.org/10.1007/s12034-009-0001-4

[25] Shulman, S., Fall, M.L. and Strickland, P. (2008) Ceramic Processing Using Microwave Assist Technology. American Ceramic Society Bulletin, 87, 34-36.

[26] Ghosh, D. and Bhattacharyya, K.G. (2002) Adsorption of Methylene Blue on Kaolinite. Applied Clay Science, 20, 295-300. http://dx.doi.org/10.1016/S0169-1317(01)00081-3

[27] Bulut, Y. and Aydın, H. (2006) A Kinetics and Thermodynamics Study of Methylene Blue Adsorption on Wheat Shells. Desalination, 194, 259-267. http://dx.doi.org/10.1016/j.desal.2005.10.032

[28] Shukla, S.P., Singh, A., Dwivedi, L., Sharma, K.J., Bhargava, D.S., Shukla, R., Singh, N.B., Yadav, V.P. and Tiwari, M. (2014) Minimization of Contact Time for Two-Stage Batch Adsorber Design Using Second-Order Kinetic Model for Adsorption of Methylene Blue (mb) on Used Tea Leave. International Journal of Scientific and Innovative Research, 2, 58-66.

[29] Elkady, M.F., Mahmoud, M.M. and Abd-El-Rahman, H.M. (2011) Kinetic Approach for Cadmium Sorption Using Microwave Synthesized Nano-Hydroxyapatite. Journal of Non-Crystalline Solids, 357, 1118-1129. http://dx.doi.org/10.1016/j.jnoncrysol.2010.10.021

[30] Gao, S., Cui, J. and Wei, Z. (2009) Study on the Fluoride Adsorption of Various Apatite Materials in Aqueous Solution. Journal of Fluorine Chemistry, 130, 1035-1041. http://dx.doi.org/10.1016/j.jfluchem.2009.09.004

[31] Badruddoza, A.Z.M., Goh, S.S.H., Hidajat, K. and Uddin, M.S. (2010) Synthesis of Carboxymethyl- $\beta$-Cyclodextrin Conjugated Magnetic Nano-Adsorbent for Removal of Methylene Blue. Colloids and Surfaces A: Physicochemical and Engineering Aspects, 367, 85-95. http://dx.doi.org/10.1016/j.colsurfa.2010.06.018

[32] Sen, T.K., Afroze, S. and Ang, H.M. (2011) Equilibrium, Kinetics and Mechanism of Removal of Methylene Blue from Aqueous Solution by Adsorption onto Pine Cone Biomass of Pinus Radiate. Water, Air, \& Soil Pollution, 218, 499-515. http://dx.doi.org/10.1007/s11270-010-0663-y 
[33] Wu, L., Forsling, W. and Schindler, P.W. (1991) Surface Complexation of Calcium Minerals in Aqueous Solution. Journal of Colloid and Interface Science, 147, 178-185. http://dx.doi.org/10.1016/0021-9797(91)90145-X

[34] Barka, N., Qourzal, S., Assabbane, A., Nounah, A. and Ichou, Y.A. (2008) Adsorption of Disperse Blue SBL Dye by Synthesized Poorly Crystalline Hydroxyapatite. Journal of Environmental Sciences, 20, 1268-1272. http://dx.doi.org/10.1016/S1001-0742(08)62220-2

[35] Corami, A., Mignardi, S. and Ferrini, V. (2008) Copper and Zinc Decontamination from Single- and Binary-Metal $(\mathrm{Cd}+\mathrm{Pb}+\mathrm{Zn}+\mathrm{Cu})$ Solutions by Sorption on Hydroxyapatite. Journal of Colloid and Interface Science, 317, 402-408. http://dx.doi.org/10.1016/j.jcis.2007.09.075

[36] Ciobanu, G., Harja, M., Diaconu, M., Cimpeanu, C., Teodorescu, R. and Bucur, D. (2014) Crystal Violet Dye Removal from Aqueous Solution by Nanohydroxyapatite. Food, Agriculture \& Environment, 12, 499-502.

[37] Sharma, P. and Das, M.R. (2013) Removal of a Cationic Dye from Aqueous Solution Using Graphene Oxide Nanosheets: Investigation of Adsorption Parameters. Journal of Chemical \& Engineering Data, 58, 151-158. http://dx.doi.org/10.1021/je301020n

[38] Bouyarmane, H., El Asri, S., Rami, A., Roux, C., Mahly, M.A., Saoiabi, A., Coradinc, T. and Laghzizil, A. (2010) Pyridine and Phenol Removal Using Natural and Synthetic Apatites as Low Costsorbents: Influence of Porosity and Surface Interactions. Journal of Hazardous Materials, 181, 736-741. http://dx.doi.org/10.1016/j.jhazmat.2010.05.074

[39] Dogan, M., Alkan, M., Türkyilmaz, A. and Özdemir, Y. (2004) Kinetics and Mechanism of Removal of Methylene Blue by Adsorption onto Perlite. Journal of Hazardous Materials, 109, 141-148. http://dx.doi.org/10.1016/j.jhazmat.2004.03.003

[40] Khan, A.A. and Singh, R.P. (1987) Adsorption Thermodynamics of Carbofuran on Sn (IV) Arsenosilicate in $\mathrm{H}^{+}$, $\mathrm{Na}^{+}$ and $\mathrm{Ca}^{2+}$ Forms. Colloids and Surfaces, 24, 33-42. http://dx.doi.org/10.1016/0166-6622(87)80259-7

[41] Kara, M., Yuzer, H., Sabah, E. and Celik, M.S. (2003) Adsorption of Cobalt from Aqueous Solutions onto Sepiolite. Water Research, 37, 224-232. http://dx.doi.org/10.1016/S0043-1354(02)00265-8

[42] Liu, R.L., Liu, Y., Zhou, X.Y., Zhang, Z.Q., Zhang, J. and Dang, F.Q. (2014) Biomass-Derived Highly Porous Functional Carbon Fabricated by Using a Free-Standing Template for Efficient Removal of Methylene Blue. Bioresource Technology, 154, 138-147. http://dx.doi.org/10.1016/j.biortech.2013.12.034

[43] Auta, M. and Hameed, B.H. (2014) Chitosan-Clay Composite as Highly Effective and Low-Cost Adsorbent for batCh and Fixed-Bed Adsorption of Methylene Blue. Chemical Engineering Journal, 237, 350-361. http://dx.doi.org/10.1016/j.cej.2014.05.018

[44] Poinern, G.E.J., Ghosh, M.K., Ng, Y.J., Issa, T.B., Anand, S. and Singh, P. (2011) Defluoridation Behavior of Nanostructured Hydroxyapatite Synthesized through an Ultrasonic and Microwave Combined Technique. Journal of Hazardous Materials, 185, 29-37. http://dx.doi.org/10.1016/j.jhazmat.2010.08.087

[45] Aarfane, A., Salhi, A., El Krati, M., Tahiri, S., Monkade, M., Lhadi, E.K. and Bensitel, M. (2014) Kinetic and Thermodynamic Study of the Adsorption of Red195 and Methylene Blue Dyes on Fly Ash and Bottom Ash in Aqueous Medium. Journal of Materials and Environmental Science, 5, 1927-1939.

[46] Langmuir, I. (1916) The Constitution and Fundamental Properties of Solids and Liquids. Journal of the American Chemical Society, 38, 2221-2295. http://dx.doi.org/10.1021/ja02268a002

[47] Freundlich, H. (1906) Adsorption in Solution. Zeitschrift für Physikalische Chemie, 57, 384-470.

[48] Mahmud, K., Islam, M.A., Mitsionis, A., Albanis, T. and Vaimakis, T. (2012) Adsorption of Direct Yellow 27 from Water by Poorly Crystalline Hydroxyapatite Prepared via Precipitation Method. Desalination and Water Treatment, 41, 170-178. http://dx.doi.org/10.1080/19443994.2012.664699

[49] Walker, G.M. and Weatherley, L.R. (2001) Adsorption of Dyes from Aqueous Solution-The Effect of Adsorbent Pore Size Distribution and Dye Aggregation. Chemical Engineering Journal, 83, 201-206. http://dx.doi.org/10.1016/S1385-8947(00)00257-6

[50] Hasnain Isa, M., Lang, L.S., Asaari, F.A.H., Aziz H.A., Ramli, N.A. and Dhas, J.P.A. (2007) Low Cost Removal of Disperse Dyes from Aqueous Solution Using Palm Ash. Dyes and Pigments, 74, 446-453. http://dx.doi.org/10.1016/j.dyepig.2006.02.025

[51] Li, C., Ge, X., Liu, S. and Liu, F. (2012) Synthesis of Novel Core-Shell Structured Hydroxyapatite/Meso-Silica for Removal of Methylene Blue from Aqueous Solutions. Advanced Materials Research, 463-464, 543-547. http://dx.doi.org/10.4028/www.scientific.net/amr.463-464.543

[52] Wei, W., Yang, L., Zhong, W.H., Li, S.Y., Cui, J. and Wei, Z.G. (2015) Fast Removal of Methylene Blue from Aqueous Solution by Adsorption onto Poorly Crystalline Hydroxyapatite Nanoparticles. Nanomaterials and Biostructures, 10, 1343-1363.

[53] Wu, F.C., Tseng, R.L. and Juang, R.S. (2001) Kinetic Modeling of Liquid-Phase Adsorption of Reactive Dyes and Metal Ions on Chitosan. Water Research, 35, 613-618. http://dx.doi.org/10.1016/S0043-1354(00)00307-9 